\title{
Comparison between the measurement of surface pressure produced by HemaClear surgical tourniquet and the pressure estimated by the manufacturer. Study in human cadavers.
}

\author{
J. Marques(1), P. Rodriguez(1), A. Valverde(2), Jl Marqués(3), E. Biosca(1), J DeAndres(1). \\ 1. General Hospital of Valencia - Valencia (Spain). 2. Faculty of Medicine of Valencia - Valencia (Spain), 3. \\ Polytechnic University of Valencia - Valencia (Spain)
}

BACKGROUND AND GOAL OF STUDY: HemaClear is the tradename of an elastic, non pneumatic narrow disposable silicone ring tourniquet to achieve both exanguination and oclusion of arterial flow. The actual pressure produced by HemaClear is unknown and uncontrollable by clinical users. In order to know the applied pressure, the manufacturer provides tables of estimated pressure, according to the HemaClear size, limb's circunference and distance from the fingers.

The purpose of this study is to measure the surface (skin) pressure produced by HemaClear and to compare it with the estimated pressure.

MATERIALS AND METHODS: The lower limb of eight cadavers were used as experimental model. Hemaclear Large Brown size was chosen in all cases. The skin pressure was measured by an electronic device made with a micro controller ATMega 328 in a Arduino Nano card, connected to resistive force sensor FSR model 402.

In each case we registered gender, limb circumference, distance from fingers, estimated pressure and measured pressure. The variables E.Press, M.Press and it difference were analyzed using the statistical software $R$ ( $R$ foundation Vienna, Austria)
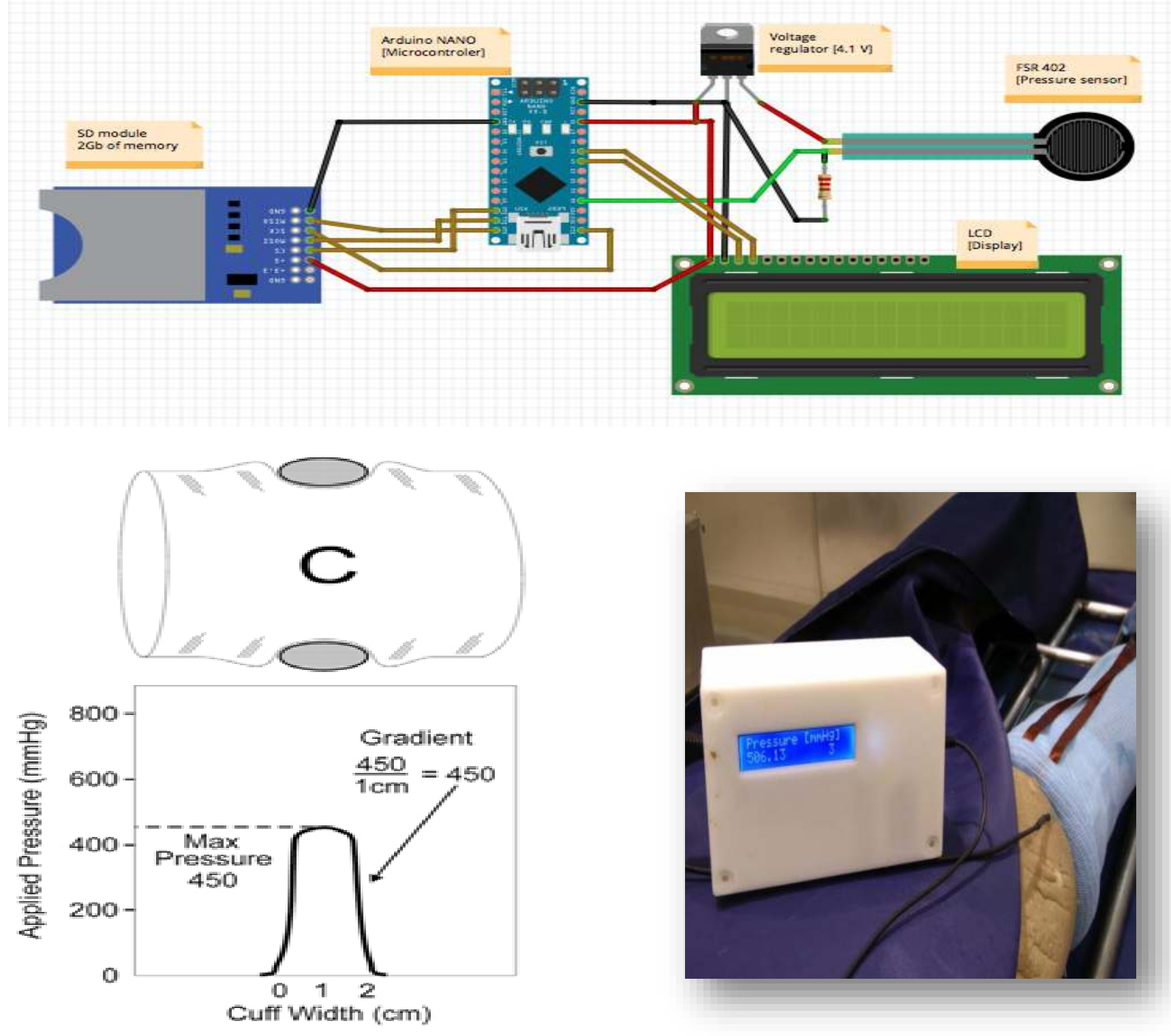

RESULTS: The mean Measured Pressure was $473 \mathrm{mmHg}$ (SD 70); The mean Estimated Pressure was 372 mmHg (SD 32); The mean Pressure difference was $100 \mathrm{mmHg}$ (SD $55 \mathrm{mmHg}$ ).

\begin{tabular}{|c|c|c|c|c|c|c|}
\hline CASE & GENDE & LIMB Q & LENGH & M.PRES & E.PRES & DIFF \\
\hline 1 & $\mathrm{~V}$ & 45 & 73 & 482 & 412 & 70 \\
\hline 2 & $\mathrm{M}$ & 43 & 73 & 500 & 389 & 121 \\
\hline 3 & $\mathrm{M}$ & 43 & 79 & 426 & 389 & 37 \\
\hline 4 & $\mathrm{M}$ & 42 & 75 & 527 & 389 & 138 \\
\hline 5 & $\mathrm{M}$ & 41 & 80 & 574 & 389 & 185 \\
\hline 6 & $\mathrm{~V}$ & 37 & 90 & 492 & 354 & 138 \\
\hline 7 & $\mathrm{~V}$ & 36 & 95 & 343 & 320 & 24 \\
\hline 8 & $\mathrm{~V}$ & 34 & 77 & 442 & 337 & 105 \\
\hline
\end{tabular}

DISCUSSION: The main complication related to clinical use of tourniquets (pneumatic and non pneumatic) is nerve injury. It is directly related to: Pressure (Force) and pressure gradient applied; Time of compression; Volume of compressed tissue.

The mechanism is the stretching of the tissue at the edges of the tourniquet and the transverse shear forces transmitted to the underlying nerves. Electronmicroscopy show paranodal mielyn rupture. Clinical studies reports a very low incidence of nerve complications related to elastic ring tourniquet: GAVRIELY (2010) report 2/100.000 incidence of not long term paresis, related to use over $120 \mathrm{~min}$; REYENDERS (2012), report 17/4870 incidence of pain or light paresis; DROSOS (2013)report 0/536 complications in orthopedic surgery

\section{CONCLUSIONS:}

1. In our cadavéric experimental model, the Measured Pressure was always higher than the Estimated Pressure.

2. The Clinical implications of this high surface pressure is unknown, but seems to be irrelevant in light of the clinical studies.

3. The narrow profile of HemaClear could reduce the stretching forces directly related with nerve injury.

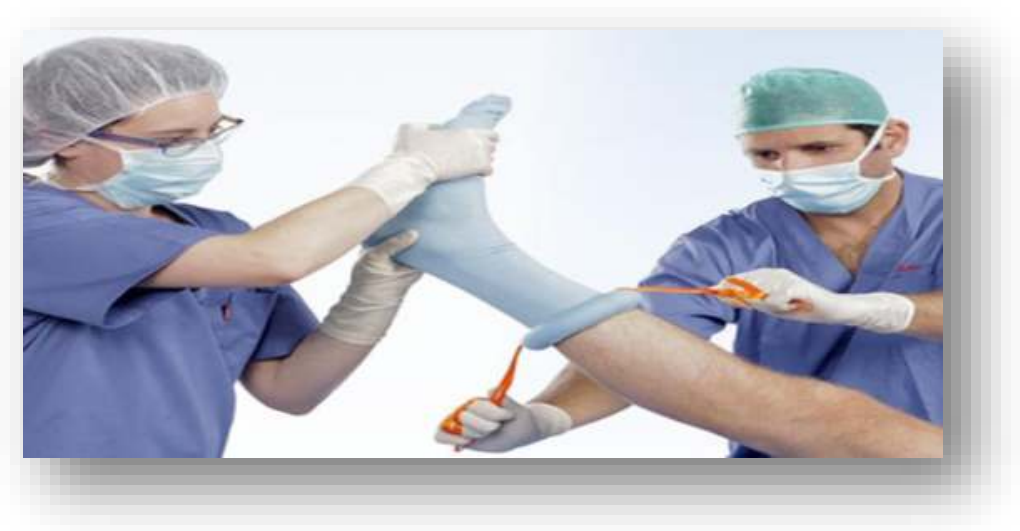

1. Shariar Noordin et Al. Surgical Tourniquettes in Orthopaedics. The Journal of Bone and Joint Surgery. 2009

2. AC McLaren et Al. The Pressure Distribution Under Tourniquets. The Journal of Bone and Joint Surgery. 1985

3. P. Bourquelot, B.I. Levy. Narrow elastic disposable tourniquet vs wide pneumatic tourniquet for creation or revision of hemodialysis angioacceses. J Vasc Access 2016; 17 (3): 205- 209

4. Jl Marqués Ortega. Instrumental Prototype of Pressure Measurement in Tourniquets https://riunet.upv.es/handle/10251/89288 